\title{
Employer Subsidies for Health Insurance Premiums: Massachusetts' Unique Experiment
}

\author{
Janet B. Mitchell", Joseph Burton and Deborah Osber
}

RTI International, 1440 Main Street, Suite 310, Waltham, MA 02451, USA

\begin{abstract}
Efforts to enroll low-income workers in premium assistance programs are constrained by the health insurance offer rates of the firms who employ them. One solution is to target premium subsidies to small firms as well as to their low-income workers, and Massachusetts is the sole state to have tried this. Firms participating in the state's Insurance Partnership were more likely to be self-employed compared with non-participating small firms. Self-employed firms receive a double bonus: assistance payments as both employer and employee. Employer participation in the program has been limited by the low income eligibility threshold and small employer subsidies.
\end{abstract}

\section{INTRODUCTION}

Premium assistance programs allow states to use public funds to help purchase employer-sponsored health insurance (ESI) coverage. By leveraging public dollars in this way, such programs allow states to cover a larger number of the uninsured working poor and their families than they could through traditional Medicaid or SCHIP programs. Premium assistance programs also allow states to enroll entire families into private health insurance plans like those enjoyed by the majority of state residents. Currently, 13 states operate premium assistance programs through the Health Insurance Premium Payment Program (HIPP) or through Medicaid/SCHIP 1115 waivers [1].

States have experienced a range of implementation challenges, including lack of employer cooperation, strict Federal criteria regarding benefit packages and cost-sharing limitations, difficulties identifying who has access to ESI, etc. [2-4]. As a result, enrollment in premium assistance programs has varied widely across states. Some policymakers view the lack of access to ESI as a major limitation of premium assistance programs. Only one-third of uninsured lowincome children are estimated to have access to ESI, for example, to have a parent working for an employer that offers health insurance coverage [5]. While uninsured workers can be found in firms of all sizes, they are disproportionately represented in small firms [6]. Health insurance offer rates have consistently been shown to decline with firm size [7]. One solution is to couple premium assistance programs for workers with some form of subsidy for their employers as well, particularly to target subsidies to small firms and their low-income employees [8].

Massachusetts has done exactly this; it implemented a premium assistance program in 1999 for both small employers (the Insurance Partnership) and their low-income workers. The Insurance Partnership (IP) was designed to both encourage some employers to offer health insurance

\footnotetext{
*Address correspondence to this author at the RTI International, 1440 Main Street, Suite 310, Waltham, MA 02451, USA; Tel: 781-434-1734; Fax: 781434-1701; E-mail: jmitchell@rti.org
}

coverage for the first time and encourage other employers to maintain their current contributions to existing policies. By offering the subsidy to employers who already offered health insurance, the program was intended to help combat crowdout. Massachusetts is the only state to offer a program targeted to employers. This article is the first one to evaluate the Massachusetts program, with a special focus on the takeup rate among eligible employers. It is the only study to describe the firms that have elected to participate in the state's Insurance Partnership. Our findings can help Massachusetts and other states assess the value of such programs.

\section{OVERVIEW OF MASSACHUSETTS' TWIN PREMIUM ASSISTANCE PROGRAMS}

While this paper is focused on the Insurance Partnership for employers, the program is designed to work in tandem with the premium assistance program for employees. Therefore, we describe each briefly below.

\section{Insurance Partnership for Employers}

Employers participating in the IP receive subsidies for each employee who enrolls in the premium assistance program (described in the following section). The subsidies were established by the state legislature and have not been increased since the IP was implemented in 1999. Employers receive $\$ 400$ annually for each individual policy, $\$ 800$ for a couple or dual (one adult/one child) policy, and $\$ 1,000$ for a family policy.

Firms must meet the following criteria to enroll in the IP:

1. Employ 50 or fewer workers;

2. Offer health insurance that meets the state basic benefit level (i.e., the benefit package required of all small group health insurers in the state);

3. Pay at least 50 percent of the premium; and

4. Employ workers who are enrolled in the premium assistance program.

The state contracts with health insurance brokers to enroll firms into the program and to make premium payments. 
The state receives federal Medicaid matching payments for IP payments only for those employers offering health insurance coverage for the first time. State-only funds are used to pay subsidies for all other employers.

Although enrollment in the IP got off to a slow start, the number of employers has steadily increased from 1,311 in 2000 to 3,498 in $2001 .{ }^{1}$ By the time of our study (2003), a total of 4,908 firms were enrolled in the IP. This represented 2 percent of all small firms in Massachusetts, but presumably a larger (albeit unknown) percentage of all eligible small firms.

\section{Premium Assistance Program for Employees}

Massachusetts uses both Medicaid and SCHIP funding for its premium assistance program. To receive premium assistance, an individual must have a gross family income less than or equal to 200 percent of FPL, ${ }^{2}$ and be employed by a firm participating in the IP. ${ }^{3}$ The size of the premium subsidy varies as a function of family income and whether the employee has children. Adults with family incomes between 150 and 200 percent of FPL, and who have children must pay \$12 per child per month toward the cost of their premium, up to $\$ 36$ per family. Adults with incomes between 100 and 200 percent of FPL, and who do not have children must pay $\$ 27$ per covered adult. The subsidy amount paid by the state is equal to the premium cost less the employer contribution and any amounts paid by individuals. Families with incomes below 150 percent of FPL, and childless adults with incomes below 100 percent of FPL, are not required to make any contributions toward their premiums.

At the time of our study, 13,202 persons were covered through the IP. These included 4,336 children and 8,866 adults. The number of adults included 6,321 workers employed by IP participating employers and 2,545 spouses who received coverage through couple or family policies. More than one-half of the adults ( 57 percent) and more than threequarters of the children (79 percent) had not been insured prior to joining the premium assistance program.

\section{DATA AND METHODS}

Samples were drawn of both IP participating firms and non-participating firms. The sampling frame for IP participants was provided by the Massachusetts Medicaid program, also known as MassHealth. The sampling frame for nonparticipants was purchased from a commercial vendor. The vendor provided a list of all businesses with 50 or fewer employees located in Massachusetts, including the selfemployed. (IP participants were deleted from this list before sampling.) Both the participant and nonparticipant lists were

\footnotetext{
Enrollment statistics in this section, and in the following one, were obtained from monthly reports generated by the Massachusetts' Division of Medical Assistance, the state's Medicaid agency. See also Mitchell and Osber [10] for more detail on the implementation of the two Massachusetts programs.

'As part of Massachusetts' recent health care reform, eligibility was expanded to 300 percent of FPL, beginning July 1, 2006. We discuss the implications of this new legislation at the end of this paper.

The program also provides premium assistance to eligible children and their parents who do not work for IP employers, generally large firms that are not eligible to participate in the IP. At the time of our study, about 3,000 children, plus their parents, received premium assistance outside the IP.
}

sorted by zipcode. After selecting a random starting point, we selected every n-th record to achieve the desired sample size This assured that the sample would reflect the geographic distribution of all small businesses in Massachusetts. Mailed questionnaires were sent to each sampled firm, with telephone follow-up of non-respondents.

The final sample for IP participants was 779 firms, for a response rate of 59 percent. This response rate is as high, or higher, than the 50 percent found for telephone surveys of business establishments nationally [7,9], which are typically higher than for mailed surveys like ours. The final sample for non-participating firms was considerably smaller, 362 firms, with a response rate of 36 percent. The most common reason for non-response was the inability to locate the firm. Comparisons of the characteristics of survey respondents and non-respondents found that non-respondents were more likely to be self-employed, and it is likely that many had gone out of business or moved in the time since the vendor's list was constructed. Employer surveys typically exclude very small firms, as well as the self-employed altogether, so we have no benchmark for comparison with this group. ${ }^{4}$ Sampling weights were created to adjust for non-response in the analyses. Weights were constructed separately for participants and non-participants, and adjusted for differences in firm size, industry type, age, and location.

\section{FINDINGS AND DISCUSSION}

\section{Firm Characteristics}

There are marked differences in the firm characteristics of employers participating in the IP with those of nonparticipating small firms (Table 1). Firms participating in the IP are significantly smaller than other small firms. (Firm size was defined as the total number of full-time employees in the firm, including the owner or sole proprietor.) In particular, almost two-thirds of IP participants are self-employed (62.2 percent), compared with only two-fifths (42.7 percent) of non-participating firms. The disproportionate enrollment of the self-employed in the IP has been noted by state officials since the inception of the program. Since the self-employed individual is both employer and employee, he/she may qualify for both IP and premium assistance payments. This makes the IP particularly attractive for those low-income self-employed who otherwise could not afford health insurance premiums.

IP participants also differ significantly from other firms with regard to industry type. The industry classifications are based on Standard Industry Classification (SIC) codes maintained by the U.S. Department of Labor. Employers in the IP are more likely to be in retail trade, construction, and personal services. Personal services include such businesses as beauty shops, dry cleaners, and daycare centers. Nonparticipating firms are more likely to be in business services, compared with IP participants. Business services include

\footnotetext{
${ }^{4}$ The annual Kaiser Family Foundation Employer Health Benefits Surveys exclude firms with fewer than 3 employees [7]. Similarly, the annual Mercer US National Employer-Sponsored Health Plan Surveys are limited to firms with at least 10 employees (http://www.mercerhr.com/referencecontent. jhtml?idContent=1258390, accessed 4/12/07). Finally, the 1997 Robert Wood Johnson Employer Health Insurance Survey excluded the selfemployed unless they had at least one employee in addition to themselves [9].
} 
Table 1. Characteristics of IP-Participating Firms and Non-Participants (Percent Distributions)

\begin{tabular}{|c|c|c|}
\hline & Participants & Non-Participants \\
\hline Size (Number of Full-Time Employees, Including Self): & & $* *$ \\
\hline One & $62.2 \%$ & $42.7 \%$ \\
\hline $2-9$ & 27.5 & 46.5 \\
\hline $10-50$ & 10.3 & 10.9 \\
\hline Industry Type (Based on SIC Codes): & & $* *$ \\
\hline Retail trade & 15.6 & 12.2 \\
\hline Personal services & 18.0 & 11.9 \\
\hline Business services & 25.6 & 37.0 \\
\hline Manufacturing & 7.5 & 9.1 \\
\hline Wholesale trade & 2.7 & 2.7 \\
\hline Transportation/communication/utilities & 3.9 & 1.7 \\
\hline Finance/insurance/real estate & 5.2 & 8.3 \\
\hline Agriculture/forestry/fishing & 4.1 & 3.6 \\
\hline Construction & 13.7 & 8.9 \\
\hline Other & 3.8 & 4.5 \\
\hline Years in Business: & & $* *$ \\
\hline 5 years or less & 26.2 & 12.7 \\
\hline $6-10$ years & 21.0 & 18.0 \\
\hline $11-15$ years & 16.5 & 16.2 \\
\hline More than 15 years & 36.3 & 53.1 \\
\hline Geographic Location: & & $* *$ \\
\hline Greater Boston & 22.4 & 40.0 \\
\hline Northeast & 14.5 & 16.1 \\
\hline Southeast, including Cape Cod & 28.7 & 22.4 \\
\hline Central & 11.0 & 8.5 \\
\hline Western Massachusetts & 23.4 & 13.0 \\
\hline
\end{tabular}

** Significantly different from IP participants at .01 level.

Survey of IP participating firms and non-participating small firms in Massachusetts, 2003.

advertising, graphic design, computer processing companies, and the like.

Firms participating in the IP are significantly less established. About one-quarter (26.2 percent) had been in business for five years or less, twice as many as non-participants (12.7 percent). Over one-half of non-participating firms had been operating for over 15 years, compared with just over one-third of participants.

Finally, IP participants are disproportionately located outside the Greater Boston area. Only one-fifth (22.4 percent) of participating firms are located in the Greater Boston metropolitan area, compared with two-fifths of non-participants. IP participants are particularly likely to be located in the rural Western part of the state (23.4 percent, compared with only 13 percent of other small firms). One possible explanation for these geographic differences may be lower average wages outside Boston, and hence relatively more eligible workers.

\section{Health Insurance Offer Rates}

One reason for non-participation in the IP may be that those employers already offer health insurance, and either are unaware of the program or do not perceive a need for assistance. This may be particularly likely, since nonparticipants also are larger firms. Health insurance offer rates have consistently been shown to be positively correlated with firm size [7]. IP participants were asked whether they offered health insurance, prior to joining the IP, ${ }^{5}$ while the question for non-participants is based at the time of interview. Surprisingly, there were no differences in offer rates; just over one-half of firms in each group offered health insurance coverage to their employees, 55.7 percent and 58.8 percent of participants and non-participants, respectively.

Firms offering health insurance coverage were asked if they offered either couple/dual coverage or family coverage.

\footnotetext{
${ }^{5}$ Since all employers must offer health insurance in order to join the IP, it would not make sense to compare their offer rates at the time of the survey.
} 
There were no differences between participating and nonparticipating firms. About one-third of firms reported that they offered couple/dual coverage, and two-thirds reported offering family coverage.

\section{Reasons for Not Offering Health Insurance Coverage}

Firms reporting that they did not offer health insurance coverage were asked to report the reason(s) why. (For IP participating firms, the question referred to reasons why prior to enrolling in the IP.) Health insurance premiums being too expensive was cited by many firms, but by significantly more of the participants than non-participants (56 percent vs. 44 percent). Nonparticipating firms were significantly more likely to report that they did not offer coverage because they and/or their employees were covered by health insurance policies purchased elsewhere, e.g., through a spouse's employer (45.5 percent, compared with only 14 percent of IP participants). After these two reasons, the most frequently cited reason (by 8.1 percent and 11.8 percent of participants and non-participants, respectively) was that their only employees were either temporary or part-time, and hence not eligible for coverage. The remaining reasons were cited by only small numbers of respondents.

\section{Learning about the Insurance Partnership}

Firms participating in the IP were asked how they had learned about the program, and to list all ways in which they had heard about it. The most frequently reported sources of information were an insurance agent/broker (mentioned by 30.5 percent of participants), through a mailing (19.9 percent), or from a friend or colleague (19.3 percent).

When the IP was first implemented in 1999, enrollment was limited to very small employers (fewer than 10 employees). The program was expanded to larger employers (up to 50 employees) the following year (2000). At this time, the state launched an extensive media campaign, using television, radio, newspapers, and billboards. Very few firms (less than $10 \%$ ) reported learning about the program from any of these media sources.

All non-participating firms were asked whether they were familiar with the IP. Less than a quarter (23.5 percent) had heard about the IP prior to the survey. These firms reported insurance agents and friend/colleagues most frequently as information sources.

\section{Reasons for Non-Participation among Small Firms}

As noted earlier, only a quarter of non-participating firms were familiar with the IP. For those firms who had not heard of the IP before, the survey instrument included a paragraph describing the IP program and its eligibility criteria. All nonparticipating firms were then asked if they would be interested in a program like the IP. About one-third (31 percent) expressed interest in the IP, and the remaining 69 percent of firms were asked why they were not interested in participating.

The most common reason for non-participation was that the firm had no low-income employees. Well over one-half of firms (55.9 percent) said they did not have any employees who met the income eligibility criteria. ${ }^{6}$ One-eighth of firms (12.8 percent) offered health insurance coverage to their employees currently, and did not need the help provided by the IP. Another 18.7 percent of employers did not currently offer health insurance, but said that the subsidy amount offered by the IP was not enough. The remaining firms reported that they only had only part-time or temporary employees, the IP involved "too much paperwork," or they "don't want to get involved with a government program."

\section{What Distinguishes IP Participating Firms from Non- participants?}

The analyses in Table $\mathbf{1}$ show that IP participating firms differed in key ways from non-participants. IP participants were more likely to be self-employed, for example, and to be located outside the Greater Boston area. To the extent that larger firms are more likely to be based in Greater Boston, then differences in location may simply be a function of firm size. In order to disentangle these differences, we estimated a logistic regression of IP participation as a function of firm characteristics.

The regression results are shown in Table 2. The two columns model the decision to participate in the IP, first as a function of firm characteristics alone and then including whether or not the firm offered health insurance coverage. The purpose of the latter was to determine whether offering (or not offering) coverage had an effect on the participation decision. The regression results are consistent with the tabular findings described earlier. Larger firms were less likely to enroll in the IP, compared with the self-employed, although the difference was significant only for those firms with 2 to 9 employees. Firms with 2 to 9 employees were only half as likely (odds ratio $=0.43$ ) to participate as the self-employed.

Firms located outside the Greater Boston area were more than twice as likely to join the IP, compared with Boston firms, even after adjusting for firm size and other characteristics. Similarly, holding these other factors constant, significant differences by industry mix persisted. IP participation also falls dramatically with the age of the firm.

Whether or not the firm already offered health insurance coverage had no significant effect on the participation decision, as indicated by the corresponding odds ratio in the second equation. Note that inclusion of the health insurance offer variable also has no effect on the direction or magnitude of any of the other firm variables.

\section{DISCUSSION}

The Insurance Partnership has succeeded in enrolling almost 5,000 small employers at present. These firms provide health insurance coverage to over 13,000 adults and children in Massachusetts, the majority of whom did not previously have health insurance. Nevertheless, total enrollment in the IP represents only a fraction of all small firms in the state. Of course, many of these non-participating firms may not be eligible for the IP, but our survey found that over

\footnotetext{
${ }^{6}$ We suspect that non-respondents among non-participating firms were more likely to have moved or gone out of business, as they could not be located by interviewers. To the extent that these latter firms may have been smaller and more likely to employ low-income workers, the importance of this reason may be over-stated.
} 
40 percent of them did not offer health insurance coverage to their employees, suggesting that they might need financial assistance. While many of these firms said their employees were able to obtain coverage elsewhere, an equal number reported that premiums were simply too expensive.

Table 2. Logistic Regressions for IP Participation (Odds Ratios)

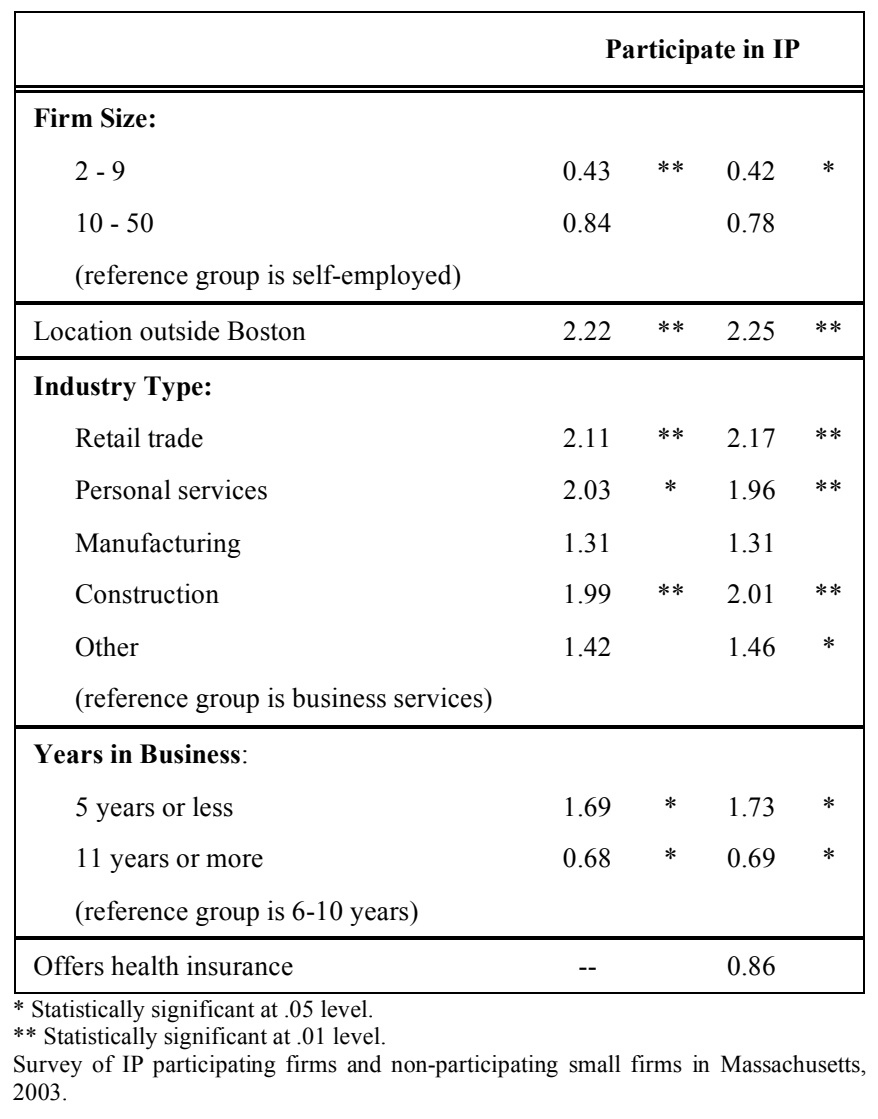

Firms participating in the IP were significantly different from other small firms in Massachusetts. They were smaller in size, younger, more likely to be located outside the Greater Boston area, and to be in the retail trade, personal services, or construction business. Despite these differences, IP participants were not any more likely to have offered health insurance coverage to their employees (prior to enrolling) than were other small firms. What motivated some firms to enroll in the IP and not others? We have identified several possible explanations.

First, IP participating firms were more likely to be selfemployed, a characteristic that predicted enrollment even after holding industry type, location, and firm age constant. Self-employed firms essentially get a double bonus. They receive the IP payment that is applied toward their 50 percent (minimum) share of the premium, plus the premium assistance payment that covers almost all of the employee's share. This results in a substantial discount (40 percent or more of the total premium) for self-employed individuals. Consider this remark from a firm participating in the IP: "The Partnership has been a God-send for us-sole proprietors. We wouldn't be able to afford health insurance on our own without this help."
Second, the majority of non-participating firms (76.5 percent) had not heard of the IP prior to our survey. Although the state had launched a major media campaign in 2000 to advertise the IP, state officials reported that they had stopped active promotion of the IP due to budget constraints.

Third, non-participating firms cited "no low-income employees" as the most important reason for not joining the IP. Yet one-half of these firms did not offer health insurance coverage to their employees, suggesting that a higher income eligibility threshold might have led to their participation. Anecdotal evidence from insurance brokers suggests that income eligibility for the premium assistance program is set too low, given the high cost of living in Massachusetts (and subsequently higher wages than the national average).

Fourth, some non-participating firms reported that the IP subsidy was not sufficient to induce them to offer health insurance coverage. The IP payment amounts have not been increased since the enabling legislation was passed in July 1997 (and the program implemented in 1999). Meanwhile, health insurance premiums have increased dramatically over the same time period.

Targeting health insurance subsidies to small firms employing low-income workers has been proposed as one means for reducing the number of uninsured [8], a policy that has been receiving increased attention in the recent financial downturn. However, two recent studies have concluded that employer subsidies actually are an inefficient mechanism for increasing insurance coverage [9, 11]. It can be difficult to identify low-wage workers through either firm size or industry type; while many are concentrated in small firms, the majority of all low-wage workers (61 percent) are employed by large firms [9]. Similarly, as also shown by our survey, many employees of small firms earn higher wages. Employers, even small employers, have also been shown to be only moderately responsive to premium costs, and that relatively large subsidies would be required to induce firms to offer health insurance coverage [11]. Both of these studies examined employer subsidies, however, without consideration of a complementary subsidy program for employees. It is reasonable to hypothesize that employer offer rates, especially among small firms, might be more responsive to subsidies that target both employer and employees. This may be particularly true for the self-employed, a group that is typically excluded from employer surveys.

The Insurance Partnership is the first, and so far only, example of a state program that actually targets uninsured workers through their employers. Subsidies are provided only to small firms, and only for those employees who qualify as low-income. Both the firm and the low-income employee receive assistance with their premium payments. The program has been successful in enrolling small firms, many of whom had not previously offered health insurance coverage. State officials speculate that the IP also may have helped other firms retain health insurance coverage in the face of double-digit premium increases over the past few years. Nevertheless, the 13,000 individuals currently insured through the IP represent only a tiny fraction relative to the estimated 418,000 uninsured Massachusetts residents [12]. 


\section{POLICY IMPLICATIONS}

Our study suggests two obvious solutions to increasing employer participation in the IP: (1) increase the income eligibility threshold above 200 percent of FPL; and (2) increase the IP subsidies to employers. Both of these solutions have major cost implications for both state and federal policymakers. The IP subsidies are borne disproportionately by the state (as federal matching payments are available only for those firms offering coverage for the first time). A third, relatively low cost, solution would be to implement a new media campaign to increase employer awareness of the IP. As one survey respondent noted: "They could make [the program] more known, advertise more. I told other business owners, and they didn't even know about it".

Since our study was conducted, Massachusetts passed its landmark health care reform bill in 2006. As part of this legislation, eligibility for the IP was expanded to 300 percent of FPL, but the IP subsidies were not changed. However, all employers with 11 or more employees will be required to make a "fair and reasonable contribution" to health coverage or face an assessment by the state of $\$ 295$ per employee per year. New research is needed to determine whether or not Massachusetts's health care reform will encourage more employers to join the IP.

\section{ACKNOWLEDGMENTS}

Funding for this study was provided by the Centers for Medicare and Medicaid Services (CMS) under contract No. 500-95-0058, task order no. 9.

We gratefully acknowledge the support and cooperation of both the Centers for Medicare and Medicaid Services (CMS) and the Massachusetts Division of Medical Assistance (DMA). The opinions in this paper are those of the authors and do not necessarily reflect those of CMS or
DMA. We would also like to acknowledge and thank our project officer, Dr. Carol Magee.

\section{REFERENCES}

[1] National Conference of State Legislatures (NCSL). Summary of employer premium assistance programs. Washington, DC: [updated 2003 July 14; cited 2006 Nov]. Available from: http://www.ncsl. org/programs/health/buyin03.htm

[2] Curtis R, Neuschler E. Premium assistance. Future Child 2003; 13(1): 214-23.

[3] Lutsky A, Hill I. Premium assistance programs under SCHIP: not for the faint of heart? Washington DC: Urban Institute 2003.

[4] Neuschler E, Curtis R. Premium assistance: what works? What doesn't? Washington DC: Institute for Health Policy Solutions 2003.

[5] Marquis MS, Kapur K. Employer transitions and continuity of health insurance: implications for premium assistance programs. Health Aff 2003; 22(5): 198-209.

[6] Garrett B. In: Henry J, Ed. Employer-sponsored health insurance coverage: Sponsorship, eligibility, and participation patterns in 2001. Washington DC: Kaiser Family Foundation 2004.

[7] Gabel J, Claxton G, Holve E, et al. Health benefits in 2003: premiums reach thirteen-year high as employers adopt new forms of cost sharing. Health Aff 2003; 22(5): 117-26.

[8] Neuschler E, Curtis R. Use of subsidies to low-income people for coverage through small employers. Health Affairs [Web Exclusive] 2003 May 21 [cited 2009 Jan 9]; 22: W3-227-36. Available from: http://content.healthaffairs.org/cgi/content/full/hlt haff.w3.227v1/DC1

[9] Long S, Marquis M. Low wage workers and health insurance coverage: Can policymakers target them through their employers? Inquiry 2001;38(3): 331-7.

[10] Mitchell JB, Osber D. Using Medicaid/SCHIP to insure working families: the Massachusetts experience. Health Care Financ Rev 2002; 23(2): 35-45.

[11] Hadley J, Reschovsky J. Small firms' demand for health insurance: the decision to offer insurance. Inquiry 2002; 39(2): 118-37.

[12] Commonwealth of Massachusetts, Division of Health Care Finance and Policy. Health insurance status of Massachusetts residents. $3^{\text {rd }}$ ed. Boston: Massachusetts Division of Health Care Finance and Policy, Commonwealth of Massachusetts 2003. 